\title{
Supporting Capacity-Building Project Characteristics Test of Zhoushan Multi-Terminal HVDC Flexible Demonstration Project
}

\author{
Guilong Liu, Ying Zhu, Siquan Lu, Youpeng Hong, Jian Wu \\ Zhejiang Provincial Environmental Radiation Monitoring Center, Zhejiang Province Key Laboratory of Environmental Radiation Safety \\ Monitoring, Hangzhou, China
}

Email address:

285505363@qq.com (Guilong Liu),778671456@qq.com (Ying Zhu),95894111@qq.com (Siquan Lu), 26328929@qq.com (Youpeng Hong),276627827@qq.com (Jian Wu)

\section{To cite this article:}

Guilong Liu, Ying Zhu, Siquan Lu, Youpeng Hong, Jian Wu. Supporting Capacity-Building Project Characteristics Test of Zhoushan Multi-Terminal HVDC Flexible Demonstration Project. American Journal of Environmental Protection. Vol. 7, No. 2, 2018 , pp. $23-28$. doi: 10.11648/j.ajep.20180702.11

Received: May 15, 2018; Accepted: June 14, 2018; Published: July 11, 2018

\begin{abstract}
In this paper, a flexible Zhoushan multiterminal HVDC test demonstration projects supporting capacity-building project for the study, the DC cables through the flexible testing ground field measurements of its surrounding environment, the DC cables of a flexible environment affect the characteristics of the test site. The results show: the project on the surrounding environment has little effect of electromagnetic radiation, which affect the field strength generated by the project on the environment is negligible, the project generated frequency electric field, power frequency magnetic fields, DC magnetic field, radio interference strength, noise are smaller than the corresponding standard limits.
\end{abstract}

Keywords: Flexible DC Transmission, Environmental Impact, Electric Field, Magnetic Filed, Radio Interference, Noise

\section{Introduction}

The flexible direct current transmission technology is a new generation of DC transmission technology featuring fully controlled power electronics, voltage source converters and new modulation technologies. Compared with traditional DC transmission technologies, it has no need for reactive power compensation and no phase change. Failure problems, simultaneous adjustment of active power and reactive power, and low harmonic levels are suitable for the construction of multi-terminal DC systems and other obvious advantages [1]. They are widely used in grid-connected renewable energy, isolated islands, urban power supply, and wind power generation. Measure the weather and choose sunny weather [2-3].

This article selects Zhoushan multi-port flexible HVDC transmission demonstration project supporting test capacity construction project as the research object, and through the field measurement of the surrounding environment of the flexible DC cable test site, the environmental impact characteristics of the flexible DC cable test site are discussed.

\section{Overview of Supporting Experimental Capacity Building Project of Zhoushan Multi-Station Flexible HVDC Transmission Demonstration Project}

Zhoushan $\pm 200 \mathrm{kV}$ five-terminal flexible DC transmission project is the first five-terminal flexible DC transmission project that has been successfully put into operation in the world. It is also the world's most flexible, direct-current DC project with the highest voltage rating, the largest number of terminals, and the largest single-ended capacity. The research object belongs to Zhoushan $\pm 200 \mathrm{kV}$ five-terminal flexible DC transmission engineering technology reserve project. At present, the first DC $200 \mathrm{kV}$ flexible DC cable pre-assessment test has been carried out in the flexible DC test site of the Zhoushan multi-terminal flexible DC transmission demonstration project. The test aims to strengthen the islands under the jurisdiction of electrical contacts, enhance the structure of the grid, improve the reliability of power supply, 
solve the flexible access of new energy such as offshore wind power, cable charging power and impact stability and power quality problems.

The main equipment in the test field of flexible DC cables is one set of $1200 \mathrm{kV} / 50 \mathrm{~mA}$ DC high voltage test equipment. It is mainly used for power cable type test, pre-qualification test, polarity reversal test and DC superimposed impulse voltage test, which can be $500 \mathrm{kV}$ and below. DC power transmission equipment withstand voltage test to provide power; Another thermal cycle system 1 set, can provide heating power for the cable system, mainly used for the heating of the cable sample conductor core. Among them, the $1200 \mathrm{kV} / 50 \mathrm{~mA}$ DC generator bears the heavy responsibility of providing test line voltage, it will be used for testing the corona characteristics and environmental impact of the line segment, as well as the on-line assessment of some equipment. It is one of the key test equipments for the base. The corona of the DC generator itself is closely related to the accuracy of future experimental results. The intensity of the corona depends directly on the surface field distribution of the generator components [4].

\section{Engineering Environmental Impact Monitoring}

\subsection{Environmental Background Value}

The monitoring results of the maximum synthetic field intensity in this project are $0.25-0.45 \mathrm{kV} / \mathrm{m}$, the $80 \%$ synthetic field monitoring results are $0.19-0.36 \mathrm{kV} / \mathrm{m}$, the DC magnetic field strength is between $48.1-49.4 \mu \mathrm{T}$, and the radio interference frequency is $0.5 \mathrm{MHz}$. The value is 39.4 52. $4 \mathrm{~dB}(\mu \mathrm{V} / \mathrm{m})[5]$.

\subsection{Measurement Items}

This study selected power frequency electric field, power frequency magnetic field, synthetic field strength, DC magnetic field, radio interference, and noise as measurement items.

\subsection{Measuring Instruments}

Measurement instruments and corresponding technical parameters are shown in Table 1.

Table 1. Measuring instruments and corresponding technical parameters.

\begin{tabular}{lll}
\hline measuring instrument & Instrument model & Measuring range \\
\hline Power frequency field analyzer & EFA300 & $\begin{array}{l}\text { Power frequency electric field:0.7V/m } \sim 200 \mathrm{kV} / \mathrm{m} ; \text { Power frequency magnetic } \\
\text { field:4nT } \sim 87 \mathrm{mT}\end{array}$ \\
$\begin{array}{l}\text { Interference field strength meter } \\
\text { Synthetic field strength meter }\end{array}$ & PMM9010/RA-01 & $0 \sim 134 \mathrm{~dB}(\mu \mathrm{V} / \mathrm{m})$ \\
Vector fluxgate magnetometer & FVM-400 & $-100 \mathrm{kV} / \mathrm{m} \sim 100 \mathrm{kV} / \mathrm{m}$ \\
Sound level meter & AWA6270+ & $-100 \mu \mathrm{T} \sim 100 \mu \mathrm{T}$ \\
\hline
\end{tabular}

\subsection{Measurement Points}

Table 2. Measurement points.

\begin{tabular}{ll}
\hline Measurement items & Flexible DC Cable Test Site \\
\hline $\begin{array}{l}\text { Power frequency electric field, power frequency magnetic field, synthetic } \\
\text { field strength, DC magnetic field }\end{array}$ & $5 \mathrm{~m}$ outside the wall of the flexible DC cable test site \\
$\begin{array}{l}\text { Radio interference } \\
\text { noise }\end{array}$ & 20m outside the wall of flexible DC cable test site \\
& Placement of 1m outside the wall of the flexible DC cable test site \\
\hline
\end{tabular}

\subsection{Equipment Operation Conditions During Measurement}

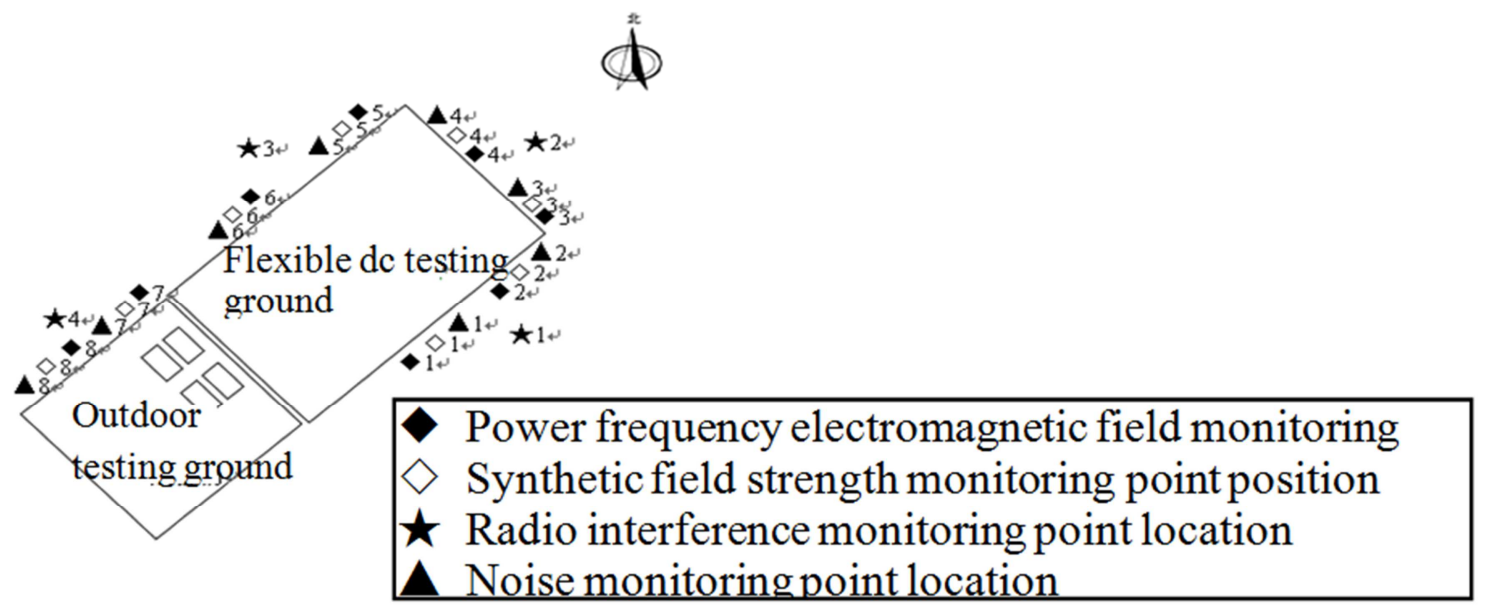

Figure 1. Schematic diagram of measurement point distribution of flexible cable test field. 
Table 3. Operating conditions.

\begin{tabular}{lllll}
\hline equipment & Primary input voltage (V) & Primary input current (A) & $\begin{array}{l}\text { High voltage output } \\
\text { voltage (kV) }\end{array}$ & $\begin{array}{l}\text { High voltage output } \\
\text { current (mA) }\end{array}$ \\
\hline $\begin{array}{l}1200 \mathrm{kV} / 50 \mathrm{~mA} \\
\text { DC voltage test device }\end{array}$ & $251.1 \sim 259.0$ & $3.9 \sim 4.1$ & $-304.0 \sim-294.0$ & $-1.40 \sim-1.20$ \\
\hline
\end{tabular}

Table 3. Continued.

\begin{tabular}{lllllllll}
\hline \multirow{2}{*}{ equipment } & \multicolumn{2}{l}{ Circuit 1 current (A) } & \multicolumn{2}{l}{ Circuit 2 current (A) } & \multicolumn{2}{l}{ Circuit 3 current (A) } & \multicolumn{2}{l}{ Circuit 4 current (A) } \\
\cline { 2 - 9 } & Test cable & Analog cable & Test cable & Analog cable & Test cable & Analog cable & Test cable & Analog cable \\
\hline $\begin{array}{l}\text { Thermal cycling } \\
\text { equipment }\end{array}$ & $751.6 \sim 814.4$ & $747.7 \sim 810.2$ & $576.1 \sim 650.7$ & $580.8 \sim 653.9$ & $564.6 \sim 633.32$ & $564.1 \sim 636.0$ & $762.7 \sim 885.2$ & $761.4 \sim 886.1$ \\
\hline
\end{tabular}

\subsection{Measuring Weather Conditions}

Choose good weather measurement in sunny days to avoid the influence of strong wind, rain, snow, hail and other weather [6].

\subsection{Measurement Results}

Table 4. Power frequency electric field intensity and magnetic field strength measurement results.

\begin{tabular}{llll}
\hline Numbering & Point name & $\begin{array}{l}\text { Power frequency electric field } \\
\text { strength(kV/m) }\end{array}$ & $\begin{array}{l}\text { Power frequency magnetic field } \\
\text { strength( } \boldsymbol{\mu} \mathbf{T})\end{array}$ \\
\hline 1 & 5m east-southeast & 0.018 & 0.174 \\
2 & 5m to the southeast middle point & 0.017 & 0.237 \\
3 & 5m to the east of the northeast & 0.028 & 0.153 \\
4 & 5m northeast of the northeast & 0.018 & 0.251 \\
5 & 5m to the northwest & 0.018 & 0.236 \\
6 & 5m to the southwest & 0.018 & 2.75 \\
7 & 5m to the northwest side of the outdoor test site & 0.018 & 4.11 \\
8 & 5m to the southwest side of outdoor test field & 0.017 & 2.12 \\
9 & Corresponding standard limit requirements & 4 & 100 \\
\hline
\end{tabular}

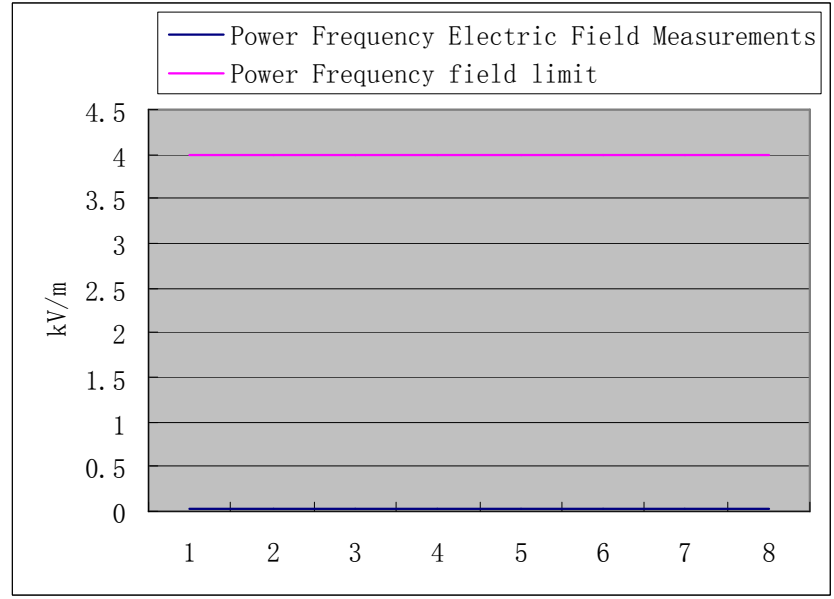

Figure 2. Power Frequency Electric Field Measurements, Limits.

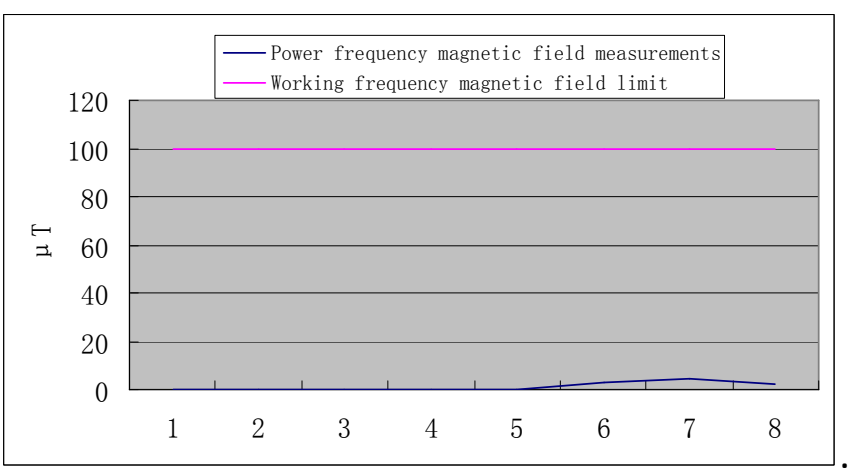

Figure 3. Power frequency magnetic field measurement, limit value. 
Table 5. Synthetic field strength monitoring results.

\begin{tabular}{llll}
\hline \multirow{2}{*}{ Numbering } & Point name & Synthetic field strength(kV/m) \\
\cline { 2 - 3 } 1 & 5m east-southeast & $\mathbf{8 0 \%}$ & -0.30 \\
2 & $5 \mathrm{M}$ to the southeast middle point & 0.10 & -0.30 \\
3 & $5 \mathrm{~m}$ to the east of the northeast & -0.10 & 0.15 \\
4 & 5m northeast of the northeast & -0.10 & -0.15 \\
5 & 5m to the northwest & -0.15 & -0.15 \\
6 & 5m to the southwest & 0.05 & -0.20 \\
7 & 5m to the northwest side of the outdoor test site & 0.10 \\
8 & 5m to the southwest side of outdoor test field & 0.05 & 0.10 \\
9 & Corresponding standard limit & 15 & 0.10 \\
\hline
\end{tabular}

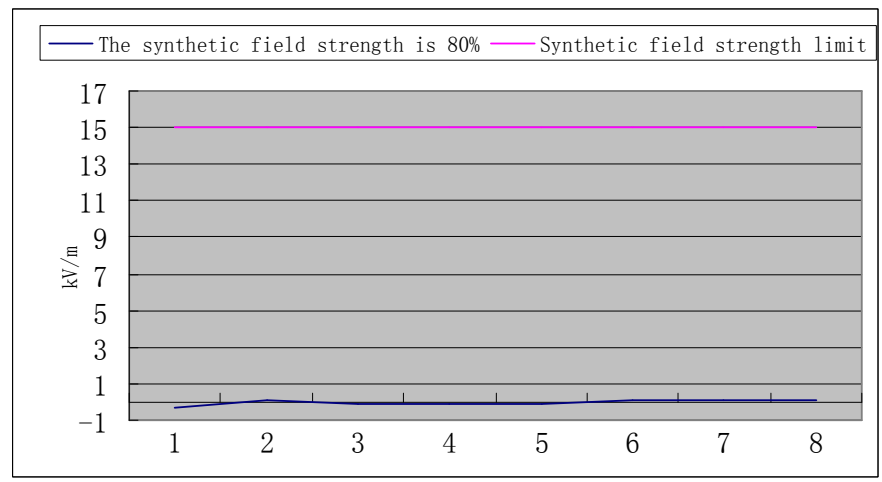

Figure 4. Synthetic field strength $80 \%$ measurement value, limit value.

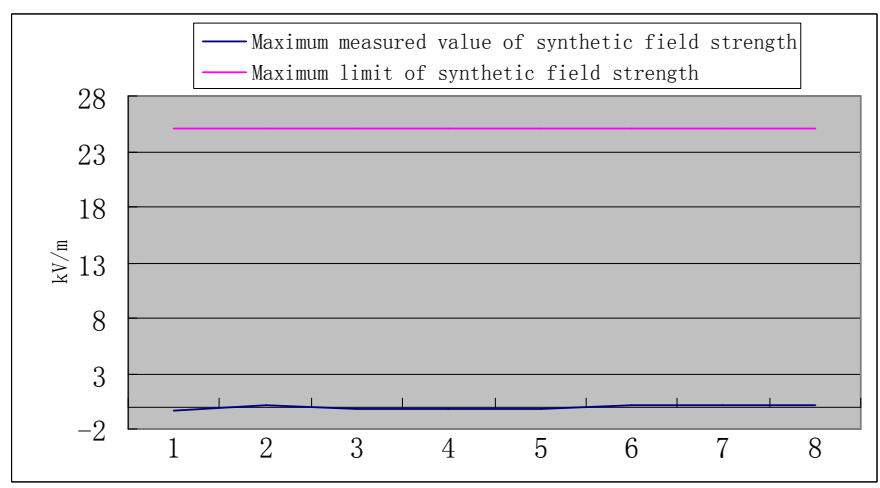

Figure 5. Synthetic field strength maximum measurement value and limit value.

Table 6. DC magnetic field strength monitoring results.

\begin{tabular}{lll}
\hline Numbering & Point name & DC magnetic field strength( $\boldsymbol{\mu T})$ \\
\hline 1 & $5 \mathrm{~m}$ east-southeast & 43.5 \\
2 & $5 \mathrm{~m}$ to the southeast middle point & 43.5 \\
3 & $5 \mathrm{~m}$ to the east of the northeast & 44.5 \\
4 & $5 \mathrm{~m}$ northeast of the northeast & 44.6 \\
5 & $5 \mathrm{~m}$ to the northwest & 50.2 \\
6 & $5 \mathrm{~m}$ to the southwest & 48.6 \\
7 & $5 \mathrm{~m}$ to the northwest side of the outdoor test site & 50.5 \\
8 & $5 \mathrm{~m}$ to the southwest side of outdoor test field & 48.2 \\
9 & Corresponding standard limit & 10000 \\
\hline
\end{tabular}

Table 7. Radio Interference Monitoring Results.

\begin{tabular}{llll}
\hline Numbering & Point name & frequencyMHz & Radio interference field strength dB( $\boldsymbol{\mu V} / \mathbf{m})$ \\
\hline 1 & 20m away from the southeast wall & 0.5 & 43.8 \\
2 & 20m away from the northeastern wall & 0.5 & 42.9 \\
3 & 20m to the northwest & 0.5 & 40.8 \\
4 & Outdoor test site 20m away & 0.5 & 48.8 \\
5 & Corresponding standard limit requirements & 0.5 & 53 \\
\hline
\end{tabular}




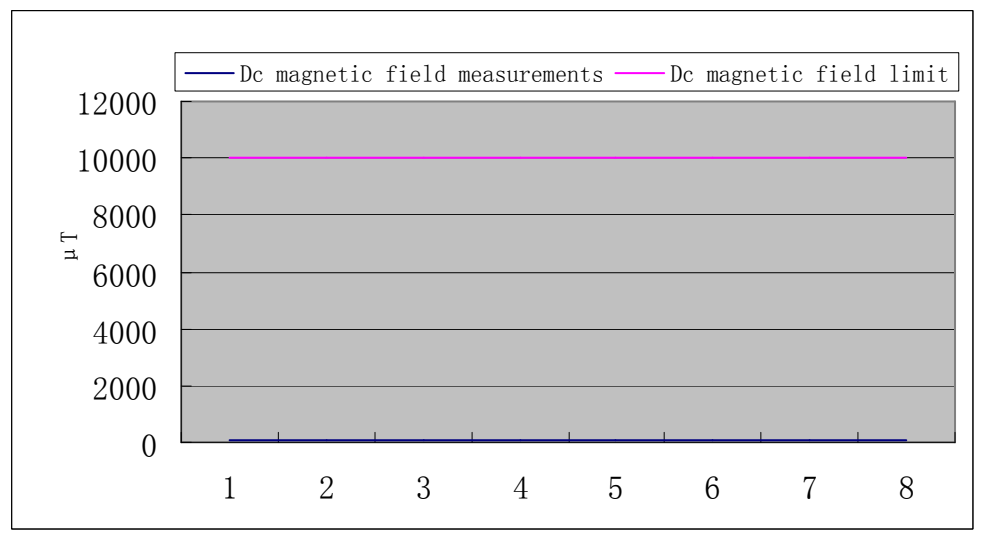

Figure 6. DC magnetic field measurements, limits.

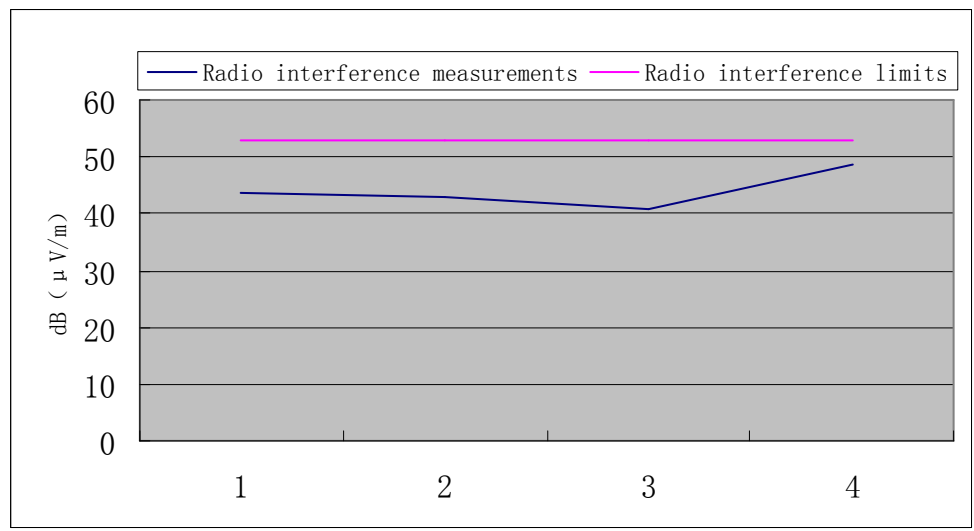

Figure 7. Radio interference measurements, limits.

Table 8. Noise Monitoring Results.

\begin{tabular}{lll}
\hline \multirow{2}{*}{ Numbering } & Point name & Noise dB(A) \\
\cline { 2 - 3 } & Daytime noise & Night noise \\
\hline 1 & 1m east-southeast & 44.8 \\
2 & 1m southeast of the middle point & 45.2 \\
3 & $1 \mathrm{~m}$ to the east of the northeast & 52.5 \\
4 & $1 \mathrm{~m}$ northeast of northeast & 54.6 \\
5 & $1 \mathrm{~m}$ to the northwest & 61.5 \\
6 & 1m to the southwest & 57.4 \\
7 & 1m to the northwest side of the outdoor test site & 55.4 \\
8 & 1m on the southwest side of the outdoor test site & 56.7 \\
9 & Corresponding standard limit requirements & 65 \\
\hline
\end{tabular}

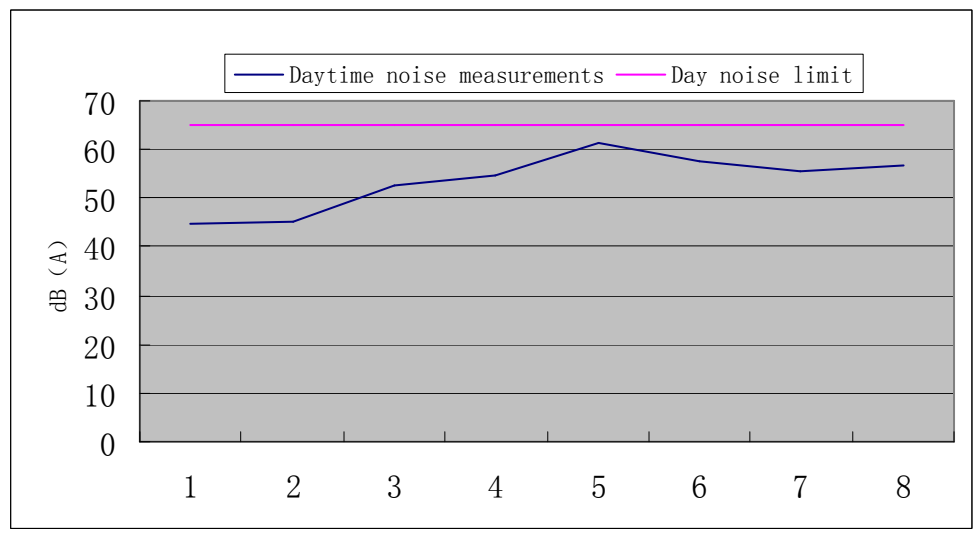

Figure 8. Daytime noise measurements, limits. 


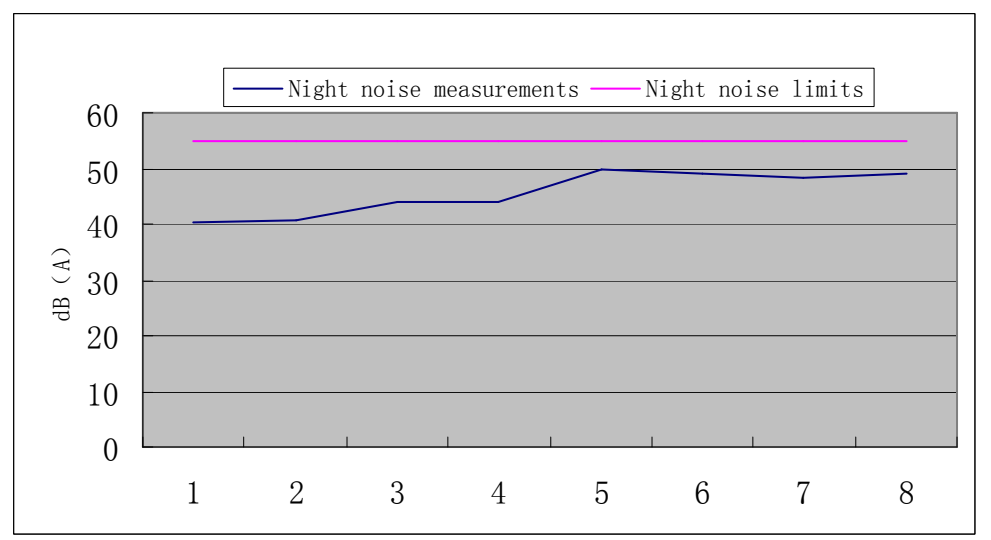

Figure 9. Night noise measurements, limits.

\subsection{Summary Analysis of Monitoring Results}

From Table 4 to Table 8, Figure 2 to Figure 9, it can be seen that the strength of the composite

Field around the test field of the flexible DC cable is basically the same as the background value of the environment.

The power frequency electric field, power frequency magnetic field, DC magnetic field strength, radio interference intensity and noise around the test field of the flexible DC cable are all less than the corresponding standard limit requirements [7-10].

\section{Conclusion}

As the first pre-qualification test of flexible DC cables in China, the results obtained from the actual measurement of the surrounding environment of the flexible DC test site in the supporting experimental construction project of the Zhoushan multi-terminal flexible HVDC transmission demonstration project show that:

The flexible DC test field has less influence on the surrounding electromagnetic radiation environment. The influence of the synthetic field intensity generated by the project on the surrounding environment is negligible; the power frequency electric field, power frequency magnetic field, DC magnetic field, radio interference intensity, and noise generated by the project are much smaller than the corresponding standard limit values.

\section{References}

[1] Xiao Hao, Zhai Zeyang, Gao Guige, Zeng Xianwen. Analysis of key technologies and prospects of flexible HVDC transmission $[\mathrm{J}]$. Electrical Engineering and Energy Efficient Management Technology, 2015, 1(17):32-38.
[2] LIU Ye, HE Weiguo, BAO Hailong, Research on flexible DC transmission technology and its application prospects [J]. 2008, 25(1):6-9.

[3] Liu Bing, Lou Jiangjun, Han Haihong, et al. Electromagnetic environment analysis of flexible HVDC transmission system [J]. High Voltage Technology, 2009, 35(11):2747-2752.

[4] Su Minghong, Sun Wei, Zhao Gang, et al. Calculation and optimization of electric field distribution of UHV bipolar DC voltage generator $[\mathrm{J}] 2008$, 44(5):402-405.

[5] Guodian Environmental Protection Research Institute, «Special Report on the Influence of Electromagnetic Environment on the Supporting Test Capability Project of Zhoushan Duplex Flexible HVDC Transmission Demonstration Project» January 2013.

[6] People's Republic of China Environmental Protection Standards, HJ 681-2013, Electromagnetic environmental monitoring method for AC electric power transmission and distribution project, November 2013.

[7] People's Republic of China Environmental Protection Standards, GB 15707-1995, Limits of radio interference from AC high voltage overhead power transmisslon lines, September 1995.

[8] People's Republic of China Environmental Protection Standards, GB 8702-2014, Controlling limits for electromagnetic environment, September 2014.

[9] People's Republic of China Environmental Protection Standards, GB 12348-2008, Emisson standard for industrial enterprises noise at boundary, August 2008.

[10] People's Republic of China Environmental Protection Standards, GB 3096-2008, Environmental quality standard for noise, August 2008. 